\title{
QUALITY MANAGEMENT AND SAFETY ASSURANCE IN HORTICULTURAL CHAINS OF BANGLADESH
}

\author{
Md. Kamrul Hassan*
}

Department of Horticulture, Faculty of Agriculture, Bangladesh Agricultural University, Mymensingh-2202, Bangladesh

*Corresponding author: Md. Kamrul Hassan, E-mail: mk_hassan2003@yahoo.com

\section{ARTICLE INFO}

ABSTRACT

Received

24.11.2014

Accepted

21.12.2014

Online

27.12.2014

Key words:

Food quality

Food safety

Pesticide

residues Heavy

metals Food

laws HACCP
Horticultural produce, especially fruits and vegetables, are rich sources of phytochemicals, namely vitamins, minerals and antioxidants. Currently, controlling quality and assuring safety of fruits and vegetables in supply chain has become one of the most challenging issues in Bangladesh. Often consumers are dissatisfied with the poor quality produce due mainly to the sub-standard postharvest handling practices. Side by side, the issue of food safety has been emerged as the most serious threat in the context of nutrition security and public health of the country. There are huge concerns over the use of harmful chemicals during production and postproduction stages. The main concerns are related to the presence of heavy metals, chemical residues and microbial contamination. Hence, immediate interventions are needed to stop any malpractice during production and marketing of fruits and vegetables. The recently introduced Food Safety Act 2013 and Formalin Control Act 2014 are two important steps from the Government of Bangladesh to deal with this deep-rooted concern. Apart from laws, various training and awareness programmes are needed so that the relevant stakeholders adopt improved practices to maintain quality and safety of produce along the supply chains. Consumption of good quality, nutritious and safe fruits and vegetables can only be assured if quality and safety control can be ensured at the production (manures, fertilizers, waters, pesticides, plant growth regulators, etc.) and postproduction (during harvesting, sorting, grading, washing, packaging, transporting, storing, processing and marketing) stages. Since, the problem is interdisciplinary and complex, there should have strong coordination among the various groups in the society including producers, traders, processors, policymakers, law enforcing agencies, researchers, physicians, civil society representatives, and other relevant GOs and NGOs in order to prevent the malpractice and improve the quality and safety situation in the horticultural chains of Bangladesh.

To cite this article: MK Hassan, 2014. Quality management and safety assurance in horticultural chains of Bangladesh. Res. Agric., Livest. Fish. 1(1): 01-11.

This article is an open access article licensed under the terms of the Creative Commons Attribution License.

www.agroaid-bd.org/ralf, e-mail: editor.ralf@gmail.com 


\section{INTRODUCTION}

Fruits and vegetables are important in the daily diet for vitamins, minerals and antioxidants. Assuring adequate intake of nutritious and safe fruits and vegetables can greatly contribute to the attainment of food and nutrition security of any nation. Unfortunately, the present rate of consumption of fruits and vegetables in Bangladesh $\left(281 \mathrm{~g} \mathrm{day}^{-1} \mathrm{capita}^{-1}\right)$ is far below the average minimum requirement of $400 \mathrm{~g} \mathrm{day}^{-1} \mathrm{capita}^{-1}$ ) (FAO/WHO 2003; BBS 2010). Due to tropical and subtropical climates, range of fruits and vegetables are grown in Bangladesh, but a considerable proportion of the produced fruits and vegetables (24-44\%; Hassan et al. 2010) never reach the consumers mainly because of postharvest losses. Hence, any attempts to minimize postharvest losses and maintain quality and safety in horticultural chains are important. The important reasons for postharvest losses of fruits and vegetables are: physiological and biochemical processes after harvest (respiration, ethylene production and transpirational loss of water), microbial decay, disorders, poor and short storage characteristics and sub-standard postharvest handling infrastructures. In addition to postharvest losses, food adulteration with harmful chemicals reached an alarming level, and is posing health hazards in the country. Peoples are suffering from food phobia. They are possibly eating less fruits and vegetables due to the perceived health risks as reported in various print and electronic media. Consequently, peoples are suffering from undernutrtion due to low intake of fruits and vegetables and are also becoming vulnerable to dreadful diseases by eating adulterated food. The widespread public concern over the presence of chemical residues in the harvested fruits and vegetables has become a burning issue in the country. The consumers are reluctant to buy fruits and vegetables that are exposed to chemicals. However, there is paucity of reliable data or documents on the levels of chemical residues (pesticides, plant growth regulators, ripening agents, preservatives, etc.) in fresh fruits and vegetables that are grown in the farmers' fields where chemical control measures are in place. To achieve complete protection of crops from pest and diseases, growers very often apply chemical pesticides in indiscriminate fashion. Consequently, many of the pests and diseases have become resistant to the currently-used pesticides. Therefore, the growers tend to use high doses of pesticides combining with increased number of applications, especially to the high value fruits and vegetables. Furthermore, fruits and vegetables are treated with plant growth regulators (PGRs) at the preharvest stage and exposed to ripening chemicals or preservatives at the postharvest stage.

The present status of government registration of these agro-chemicals and their impacts on human health merit investigation. It appears that fresh fruits and vegetables being consumed by the people could have the levels of residues that far exceeded the FAO-recommended maximum residue limits (MRLs). Therefore, food safety issues need to be exhaustively investigated to know whether the current levels of chemical residues in fruits and vegetables are still below the critical level or it exceeded the FAO-recommended MRLs and silently killing the people of the country. In the recent years, the number of patients with cancer, and heart and kidney diseases, are sharply increasing as a result of food adulteration and taking heavy toll on public lives (Morol 2004; Rasul 2014). The present paper attempts to review the relevant literatures, especially in the context of Bangladesh, in relation to the present status of control of quality and safety of fruits and vegetables in horticultural chains.

\section{QUALITY MANAGEMENT}

Nowadays, the consumers are very quality concern. The perception of quality varies with the type of users of a particular produce. Broadly, quality is a combination of factors that are based on the users' preference. For a consumer, the important quality criteria include: appearance, size, shape, colour, texture, defects, flavor, nutritional values, etc. Visual quality is the single most 
important factor that affects the sales of a produce at the retail levels. Hence, quality control is very important for both domestic and international markets. Proper care is needed to maintain optimal quality of fruits and vegetables at all levels of marketing (assembling, cleaning, sorting, processing, packaging, etc.). For quality control and quality assurance of produce several factors need to be considered as detailed in the National Food Policy 2006 (NFP 2006), and the factors are: formulation of uniform arrangement; setting of standards; capacity strengthening for grades and standards of food products; investment in packing and packaging; safe storage; and develop and enforce appropriate regulatory mechanism to control the indiscriminate use of harmful additives, preservatives and toxic elements in production and marketing. As the high-value product value chain is more demanding in food safety and quality standards, greater attention is required for certification and quality enforcement. Initiatives are needed to improve controls over pesticide use, improve food safety standards and reduce contamination. Improved pre- and postharvest practices are crucial in managing quality and assuring safety of horticultural produce in supply chain. Thus adequate measures must be taken at every step of the supply chain from production through harvesting, postharvest handling, processing, packaging, storage and marketing of produce. To start with, the GAP (Good Agricultural Practices) needs to be in place to produce and market good quality fruits and vegetables.

\section{FOOD SAFETY IN HORTICULTURAL CHAIN}

The current issue of food safety has created great impacts on the consumers' purchase behavior of food. Many consumers simply stopped buying certain types of fruits and vegetables. Many of them purchase fruits and vegetables very cautiously. The consequent less intake of fruits and vegetables may further worsen the malnutrition situation in the country. Safety related issue should be handled with utmost care by the all corners. Food may not be safe due to various reasons like adverse weather conditions, inappropriate handling, inappropriate use of agrochemicals and so on. The present food safety issues in Bangladesh are mainly concerned with food-borne illness; use of non-recommended agrochemicals (pesticides, PGRs, ripening agents, etc.); and paucity of technical experts in the detection and assessment of food adulteration. There is also lack of sufficient national standards to measure food safety and lack effective institutional mechanism to enforce food safety at different stages in the food chain. Continued research to develop easy to use practical testing kits to identify chemicals, pesticides, additives, preservatives, toxic elements, etc. at the production, processing, distribution and consumption levels is essential. To go along with the increasingly important food safety requirements for high-value products, investments are needed in laboratory and testing infrastructures to make them compatible with international standards.

In the National Food Policy Plan of Action (NFPPoA) 2008-2015, food safety and quality issues have been given due importance (NFP 2008). The main safety related concerns are adulteration and contamination by heavy metals, microorganisms, toxins and chemical residues. All stakeholders in supply chain including supply side (producers, transporters, processors and merchants); government inspection and regulatory authorities, support institutions (labs, training centres, etc.), and consumers have responsibilities to ensure safety of food products and protect consumers' health. In addition to traditional GAP, control operations relying on hazard analysis and risk prevention are to be made mandatory, especially in the case of large scale production and processing facilities. Systematic approach to identify, assess and control of hazards is known as HACCP (Hazard Analysis and Critical Control Points). Introduction of HACCP-based food safety system may be difficult for small-scale enterprises but possible for large industries. This will be best achieved by strengthening coordination among food industry, educational and training organizations and government authorities. The horticultural chain in Bangladesh is quality long and 
produce reaches the consumers through a number of middlemen (Hassan et al. 2012). So, food contamination may occur at any points of the supply chain. Contamination of food is at rampant and is contributing to the serious health hazards in Bangladesh. Rasul (2014) reported various types of food contamination including intentional (e.g. lead chromate in turmeric powder- paralysis), natural (e.g. oxalic acid in spinach- renal calculi), negligent (e.g. Salmonella typhoid) and accidental (e.g. release of radioactive particles from Chernobyl nuclear power explosion). Some of the important challenges related to quality and safety with special reference to fruits and vegetables are reviewed in the following.

\section{HEAVY METALS}

Presence of heavy metals, namely arsenic (As), lead (Pb), mercury $(\mathrm{Hg})$, cadmium (Cd), chromium ( $\mathrm{Cr}$ ), etc. in food, is one of the important threats related to food safety. The extent to which the population of Bangladesh is exposed to food contamination by toxic heavy metals is not widely available. It is apprehended that rice and vegetables used in the daily diets might have elevated levels of heavy metals (Islam et al. 2009; Jahiruddin et al. 2009). The possible sources for heavy metals in food include: contaminated waters and soils; inadequately composted manures (e.g. poultry manure); pollution of water bodies with industry wastes, and so on. Research reports related to the presence of heavy metals in edible fruits and vegetables are meager in Bangladesh. Nonetheless, Naser et al. (2011) examined the levels of heavy metals in some leafy vegetables, namely spinach, red amaranth and amaranth. When the samples of spinach, red amaranth and amaranth were analyzed the levels of cadmium $\left(0.58,0.34\right.$ and $0.48 \mu \mathrm{g} \mathrm{g}^{-1}$, respectively) and chromium $\left(6.20,5.70\right.$ and $4.81 \mu \mathrm{g} \mathrm{g}^{-1}$, respectively) were found higher than the maximum allowable limits set by the World Health Organization (WHO). As per the WHO the allowable levels of $\mathrm{Pb}, \mathrm{Cd}$, $\mathrm{Ni}$ and $\mathrm{Cr}$ are 2.0, 0.02, 10.0 and $1.30 \mu \mathrm{g} \mathrm{g}^{-1}$, respectively (Lone et al. 2003). However, the levels obtained in the present study were lower than the maximum allowable limits as set by the Prevention of Food Adulteration Act (PFA) 1954, India (2.5, 1.5, 5.0 and $20.0 \mu \mathrm{g} \mathrm{g}^{-1}$ for Pb, Cd, Ni and $\mathrm{Cr}$, respectively) (Lokeswari and Chandrappa 2006). Islam et al. (2013) reported that $94 \%$ males from the poor households and $78 \%$ males from the non-poor households had Cd intake above maximum permissible limit $\left(50 \mu\right.$ day $^{-1} 60 \mathrm{~kg}$ body weight $\left.{ }^{-1}\right)$. The report also indicated that both the poor and non-poor households of the selected areas of Bangladesh had high intakes of As and $\mathrm{Pb}$ from different foods and are at potential risk from $\mathrm{As}$ and $\mathrm{Pb}$ contamination.

\section{MICROBIAL CONTAMINATION}

Another type of contamination is the microbial contamination of food like fruits, vegetables, street vending food, semi-processed and processed food, salad, etc. due to various microorganisms. Microbial contaminations due to negligence would include typhoid (Salmonella), dysentery (Shiegella), food poisoning (Staphylococci), botulism (Clostridium botulinum) and aflatoxin (Aspergillus flavus). The important reasons for microbial contamination include: contaminated inputs (soil, water, fertilizers, etc.), poor and unhygienic postharvest handling of food commodities, preparation of food in unhygienic conditions, use of poor quality ingredients for the food preparation, and lack of personal hygiene during food handling and food preparation. For example, it is worth to mention the recent food borne illness caused by the consumption of fresh watermelon in the Kushtia and Manikganj districts of Bangladesh, where several people died and dozen fell sick after eating watermelon. Initially, it was suspected that contamination would have occurred due to the use of colouring agent into the fruit to brighten the pulp (Anon. 2014a).

To confirm the speculation, samples of watermelon from the same batch that caused food poisoning were collected from the vendor and sent to the National Food Safety Laboratory, Institute 
of Public Health (IPH) for testing. No trace of hazardous chemicals including formalin, organophosphorus, artificial dye and organochlorine compounds were found in the watermelon samples. Result revealed that the poisoning was due to the contamination of watermelon by bacterial which may have entered into the fruit through the cracks or bruises or injuries (Anon. 2014a; Anon. 2014b; Shahriar 2014). However, the role of residues of chemicals in such incident cannot be ruled out since similar outbreak occurred in the USA in 1984 (Green et al. 1987). It was the largest food borne illness caused by pesticide residues resulted from the consumption of aldicarb-contaminated watermelons. In that incidence in Oregon of USA 264 reports were received where 61 definite cases were identified. Residues of aldicarb, a cholinesterase inhibitor, were found in 10 of 16 tested watermelon samples which had been eaten by persons. The outbreak demonstrated the need for enhanced physician vigilance with respect to anticholinesterase intoxication. It also demonstrated the value of an established system for reporting of unusual illness to the public health officials.

\section{PESTICIDE RESIDUES}

There exists various human-induced food adulteration during farm and industrial production and marketing. One of the important human-induced safety concerns is the presence of pesticide residues in food, which is possibly resulted from the use of non-recommended pesticides; use of overdoses of pesticides; application of pesticides at shorter intervals; non-compliance to the withholding period (minimum duration between last application and harvest); application of cocktail of pesticides; ignorance of the users; lack of motivation; lack of proper and adequate media campaign; and exploitation by the agents of the pesticide suppliers. For instance, growers of brinjal in Bangladesh apply pesticides to control different pests and diseases. The growers often use insecticides and fungicides along with PGRs as cocktail. The major insecticides for controlling brinjal pests are of Cypermethrin (Superthion) and Dimethoate (Tafgor 40EC) groups, whereas the major fungicides are Dithane M-45, Thiovit, Minicaper and Redomil (Hassan et al. 2010). Consumers are reluctant to buy chemical-sprayed fruit and vegetables to avoid health risks.

A considerable proportion of the chemicals would present in the edible portion of vegetable as residues. Bhuiyan et al. (2009) observed that the levels of pesticide residues would be beyond the MRLs if harvested earlier than the recommended withholding period. They reported that the levels of MRLs of Ripcord insecticide (Cypemethrin group) of brinjal collected from Tangail and Norshingdi districts of Bangladesh were 0.37 and $0.67 \mathrm{ppm}$, respectively at 3 days after spraying. Alam et al. (2011) also reported that higher level of residue of pesticide was found in brinjal. Residue level of 0.95-3.30 ppm of Cartap (a.i.) was found when brinjal was sprayed with Cartap at a rate of $2.5 \mathrm{~g} \mathrm{~L}^{-1}$. The observed level was much higher than the MRL of $0.50 \mathrm{ppm}$. The study revealed that use of pesticide to reduce insect infestation is in increasing trend which could be detrimental to mankind as well the environment. Another important piece of research was conducted by Islam et al. (2011) who examined the levels of pesticide residues in 42 samples of vegetables (brinjal, cauliflower and country bean) by GC (Gas Chromatograph) with Thermionized Detector (FTD) and Electron Capture Detector (ECD). Results revealed that out of 42 samples 27 had residues, and amongst the 27, 14 samples had residues above the MRL. The detected pesticides included Diazinon, Malathion, Quinalphos, Fenitrithion, Cypermethrin, Fevalerate and Propiconazole. The MRLs vary with crops, and the MRLs for Fenvalerate; Diazinon; Quinalphos; Malathion; Cypermethrin; Fenitrothion and Propiconazole in brinjal and country bean are 0.20 and 1.00; 0.50 and $0.50 ; 0.20$ and $0.20 ; 0.50$ and $2.00 ; 0.20$ and $0.05 ; 0.10$ and 0.10 ; and 0.20 and 0.10 $\mathrm{mg} \mathrm{kg}^{1}$; respectively (FAO 2002). 


\section{RESIDUES OF PLANT GROWTH REGULATORS (PGR)}

The application of plant growth regulators in the fruit development stage has important effects on the quality parameters of fruits. Range of plant growth regulators like gibberellins, cytokinins and auxins are applied to plants to improve fruit qualities (Hofman 1998). Pradhan et al. (1988) observed that the application of gibberellins during fruit development increased fruit weight. Cytokinin and auxin have been reported to increase shelf life and reduce fruit splitting in persimmon and citrus, respectively (Almela et al. 1994; Itai et al. 1995). In Bangladesh, PGRs are used to increase the size of the edible portion of fruits and vegetables and to obtain early bearing. In the case of mango, maximum growers of Chapai Nowabgonj and Rajshahi apply PGRs from the stage of flowering to entire harvesting season. The PGRs, namely Biogeem, Ferti and Yield are used in the production of mango in Chapai Nowabgonj and Rajshahi districts of Bangladesh (Hassan et al. 2010). In the case of banana, majority of growers of Ghatail and Shakhipur Upazillas under Tangail district of Bangladesh apply PGRs to banana crops from the stage of flowering to the entire harvesting season at the rate of 5-15 mL 10-16 $\mathrm{L}^{-1}$ of water. Among different PGRs, Okozim, Planofix, Agron and Voxal Super are most commonly used by the banana growers (Hassan et al. 2010). Similar findings were also reported by Bhuiyan et al. (2009), who mentioned that 40.70 and $30.70 \%$ of the banana growers were found to be the low to medium users of PGRs in banana cultivation, especially for quick maturity and high yield. Litchi is one of the most important commercial fruits of Bangladesh that received large amounts of PGRs of various trade names including Okozim, Planofix, Pencozeb, Litosen, Voxal Super, Vitaplus, Phenphen and Folimore (Hassan et al. 2010). It is apprehended that there may have higher levels of residues of the applied PGRs in the edible portions of fruits and vegetables. The possible reasons may be the use of PGRs applied often at higher doses and at shorter intervals. Different PGRs are sometimes mixed together and applied as cocktail. However, reports related to the levels of residues of the applied PGRs in fruits and vegetables are not available. This is well understood that dozen of PGRs are used in the horticultural production in Bangladesh but the levels of their residues have not been investigated.

\section{RIPENING CHEMICALS}

Bangladesh is facing another typical problem of using synthetic chemicals (calcium carbide and ethephon) in accelerating ripening of climacteric fruits like mango, banana, papaya, tomato and jackfruit. Some non-climacteric fruits like pineapples are also being exposed to ripening chemicals. Calcium carbide is banned and ethephon-based formulations are not recommended for fruit ripening in Bangladesh. Actually, for commercial agriculture accelerated fruit ripening is recommended all over the world for uniform ripening, taste and quality and to facilitate marketing. In the developed country ethylene gas is used to accelerate ripening of climacteric fruits (Wills et al. 2004). This is healthy, and it does not pose any threat to human health. By contrast, in Bangladesh, different types of liquid plant growth regulators, namely Harvest, Profit, Tomtom, Ripen, etc. containing ethephon as active ingredient are sprayed on the fruits or the fruits are dipped into the solution of ripening chemicals (Hassan 2010; Hassan et al. 2010, Whahid et al. 2011). These chemical formulations are not recommended for fruit ripening in Bangladesh but being used by the growers and traders since there are no alternatives. Growers often use these chemicals at higher doses as compared to the dose mentioned on the label. An experiment was undertaken by Whahid et al. (2011) to examine the effects of concentrations of these ripening agents (although not recommended) on the rate of ripening. Results suggested that the concentration mentioned on the label $\left(1 \mathrm{ml} \mathrm{L}^{-1}\right)$ had the same rate of ripening as that of the half of the concentration $\left(0.5 \mathrm{~mL} \mathrm{~L}^{-1}\right)$. Although there are opinions in favour of using the chemicals (Islam 
2008), vast majority of the people of the country are opposing to the use of ripening chemicals (Shajal 2008). Accordingly, the Government of Bangladesh have imposed ban on using calcium carbide to accelerate fruit ripening in Bangladesh. The law enforcing agencies of Bangladesh are also in regular vigilance to nab and fine the peoples who are involved in such kinds of activities. At the same time they destroyed hundreds of thousands of fruits that were subjected to chemical spray (Anon. 2009; Anon. 2010a; Anon. 2010b). Hence, in depth investigation is needed to develop/optimize safe method of fruit ripening. The best option is to use ethylene-induced ripening technology (Wills et al. 2004; Hassan 2010). Apart from that, various natural methods like smoking and use of high ethylene-generating fruits (banana, apple) can be used to accelerate ripening. Whahid et al. (2011) reported that although ethephon-based formulations like Profit and Harvest resulted in faster rates of ripening but caused rapid spoilage, higher incidence of diseases and shorter shelf life of banana. On the contrary, the non-chemical techniques (smoking and ethylenegenerating fruits) resulted in faster rates of ripening (slightly slower than ethephon) but caused lower incidence of diseases, less spoilage and longer shelf life.

\section{MISCELLANEOUS}

Use of harmful preservatives has recently been reported as another dimension of food adulteration in Bangladesh. Anecdotal evidence suggests that some fruits along with fishes and milk are preserved with harmful preservatives like formalin (a dangerous chemical liable for various types of cancer). Use of food colours is also an important concern in relation to safety. Foods are prepared with various toxic colours, which may cause indigestions, allergies, asthma, cancer, etc. Apart from that, seriously unhygienic environment of the production, handling, processing and preparation of food; and storing and selling of date-expired produce; are also serious concerns. Another concern is the introduction of GMO (Genetically Modified Organism). Technically, GMO is good, but prior to introduce any GMOs, extensive investigation should be carried out so that it does not impose any impacts on the existing agricultural systems in Bangladesh.

\section{PRESENT FOOD SAFETY RESEARCH IN BANGLADESH}

Food safety is an important concern all over the country. However, research related to food safety is still unnoticeable. Nonetheless, some important research projects have been undertaken in the recent past. The Bangladesh Food Safety Project (started in 2012 for 3 years), funded by the Embassy of the Kingdom of the Netherlands and implemented by FAO aims at stronger food safety and quality control across the food chain, increased visibility of food safety related matters and an increased capacity to deal with food safety issues at all levels across the food chain in Bangladesh. The project is supporting in the development of a food safety system by strengthening and enhancing the national food safety analysis capacity (National Food Safety Lab and the Bangladesh Food Safety Lab Network); standards formulation based on risk assessment; institutionalization of food safety; preventive risk-based control; public awareness and education; food-borne illness surveillance; capacity in identified sub-sectors of the food industry to enhance food safety and facilitate improved market access (poultry, fisheries, horticulture). A research under NFPCSP (National Food Policy Capacity Strengthening Programme) elaborated the present status of using various recommended and non-recommended agrochemicals (pesticides, PGRs, ripening chemicals, etc.) in the commercially important fruits and vegetables of Bangladesh (Hassan et al. 2010). Another research project under the NFPCSP investigated the levels of heavy metals in 80 food samples collected from Gulshan, Karwan Bazar and Hazaribagh. The samples were digested with ultra pure grade nitric acid and hydrogen peroxide and analyzed using ICP-MS. Results revealed that rice and vegetables grown in Rajshahi and Jessore had elevated concentrations of 
arsenic as compared to those grown in Savar, Hazaribagh and Mymensingh regions. The entry of heavy metals into the food chains was mainly from industrial effluents, phosphatic fertilizers (e.g. $\mathrm{Cd}$ ) and burning of fossil fuels (e.g. Pb) (Islam et al. 2013). Another similar project implemented in the Department of Food Technology and Rural Industries of Bangladesh Agricultural University (BAU) where the challenges and constraints of quality control and harmful chemicals and adulterants in the case of processed food products have been summarized (Uddin 2013).

\section{FOOD SAFETY LAWS IN BANGLADESH}

Presently, there are about 17 laws in Bangladesh to regulate safe food delivery to the consumers. The laws are: i. Penal Code, 1860 (PC 1860); ii. Control of Essential Commodities Act, 1956 (CECA 1956); iii. Food (Special Courts) Act, 1956 (FA 1956); iv. Pure Food Ordinance, 1959 (PFO 1959); v. Cantonments Pure Food Act, 1966 (CPFA 1966); vi. Pesticide Ordinance, 1971 (PO 1971); vii. Special Powers Act, 1974 (SPA 1974); viii. Fish and Fish Products (Inspection and Control), Ordinance, 1983 (FFPO 1983); ix. The Breast-Milk Substitutes (Regulation of Marketing) Ordinance, 1984 (BMSO 1984); x. Bangladesh Standards and Testing Institution Ordinance 1985 (BSTIO 1985); xi. Iodine Deficiency Disorders Prevention Act 1989 (IDDPA 1989); xii. Vokta Odhikar Songrokkhon Ain, 2009 [Consumers Rights Protection Act 2009]; xiii. Sthanio Sarkar (City Corporation) Ain, 2009 [Local Government (City Corporation) Act 2009]; xiv. Sthanio Sarkar (Paurashava) Ain, 2009 [Local Government (Paurashava) Act, 2009]; xv. Mobile Court Ain, 2009 [Mobile Court Act, 2009]; and xvi. The Food Safety Act 2013 with a provision of Food safety court in each Upazila has been enacted. In this Act, the Bangladesh Food Safety Authority (BFSA) has been incorporated to help coordinate consumer protection activities across the food control system. For various offense related to food adulteration or use of harmful agents in food range of punishments have been included, and the maximum penalty as fixed in the law is 5 years imprisonment along with a fine of BDT 20 lakh (Food Safety Act 2013). The most recent inclusion in the list is the Formalin Control Act 2014, where the highest punishment of misuse of formalin has been fixed at life term imprisonment. Alongside the jail term, provision for fine of BDT 20 lakh has also been made in the Act. Besides, formalin import, production, transportation, hoarding, sale and use without license will not be allowed (Anon. 2014c). In a nutshell, Bangladesh possesses adequate number of laws for assuring safety of food but the food is possibly most unsafe here in the country. Most of the laws paid much emphasis on punishing the wrong-doers. Conceptually, the citizens of the country would have been better served by taking measures to prevent the offence so as to avoid interruption of businesses and destruction of foods. There should have provisions for monitoring, research, quality control, management, prevention, correction, consumer education, etc. so that adulteration could be prevented and the delivery of high quality, nutritious and safe fruits and vegetables could be ensured.

\section{IMPROVEMENT OF QUALITY AND SAFETY IN HORTICULTURAL CHAIN}

From the above reviews it is clear that there are true concerns over the consumption of poor quality and unsafe fruits and vegetables. Adoption of improved practices and prevention of contamination at various stages of horticultural chains are the best options for maintaining quality and safety. To deal with this deep rooted problem, number of activities to be undertaken such as: reviewing of the existing laws and their possible modernization (if needed), reviewing the findings of the relevant research projects and use the findings as evidence for any intervention; identify the bottlenecks in horticultural chains at which quality deterioration/contamination/adulteration/etc. occurs; reviewing all agro-chemicals (pesticides, PGRs, ripening chemicals, food colourings, preservatives, etc.) and find their legal status (registered or non-registered); and identify the 
reasons why growers/traders/entrepreneurs are adopting the non-recommended agro-chemicals. Farm to fork quality and safety assurance approach is to be introduced rather than inspecting the final products when nothing could be done but to destroy the product. Available technology/approaches/best practices in home and abroad are to be reviewed and the best practice(s) to be selected for the improvement of quality and safety in the horticultural chains of Bangladesh. If necessary, there may be a need to optimize the technology or practices for its dissemination to the end users. Very often, the concerns of safety in horticultural chain are due mainly to the inappropriate use of various agro-chemicals during production, handling and processing. So, intervention is to be started from production until consumption. Even though difficult for small-holders but adoption of HACCP-based quality management in the entire supply chain is needed for improvement of quality and safety of produce. The holistic approach of HACCP would include: identification of hazards, assessment of hazards, identification of the critical control points (CCP) in supply chain, identification of the critical limits, control of hazards, and monitoring and record keeping. This approach would create a revolution in the food industry in Bangladesh. It will contribute to the expansion of the domestic and international markets for the fresh and processed horticultural commodities.

Finally, to assure quality and safety in the horticultural chains in Bangladesh various options are to be performed such as: massive awareness-raising programme; preparation and distribution of appropriate training materials (manual, leaflet, poster, short film, music video, etc.); capacity strengthening of the relevant departments (DAE, universities, research institutes, etc.); capacity enhancement for analytical facilities i.e. expansion of accredited laboratories; adoption of improved practices during production and postproduction stages of the supply chain (preharvest use of inputs, harvest maturity and harvesting methods, sorting, grading, washing, packaging, transportation, storage, etc.); consumers' awareness with regards to purchase criteria, handling, processing for cooking, cooking, storage, food borne hazards; immediate measures for any incidence of food-borne illness; research and training in relation to risk assessment, risk prevention, risk control, risk exposure; reliable and quick analytical method for chemical residues and microbial contamination; co-ordination among relevant ministries; selection of competent personnel for various activities; create facilities for short, medium or long-term preservation of perishables (for instance, cool stores or various other applicable techniques for shelf life extension); etc.

\section{CONCLUSION}

Presently, controlling quality and assuring safety in horticultural chains of Bangladesh is one of the most important concerns. Consumption of good quality, nutritious and safe fruits and vegetables can be assured if quality and safety control can be ensured at the various levels including production, harvesting, sorting, grading, washing, packaging, transporting, storing, processing, marketing and consumption. From the lessons learned from the past interventions, it is noticed that only the law enforcement agency cannot not completely resolve the problem since the solution is interdisciplinary and complex. There should have strong coordination among the various groups like producers, traders, processors, policymakers, law enforcing agencies, researchers, physicians, civil society representatives, other relevant GOs and NGOs to achieve the objective of assuring quality and safety in the horticultural chains of Bangladesh.

\section{COMPETING INTEREST}

The author declare that they have no competing interests. 


\section{REFERENCES}

1. Alam MM, MZH Mondal, DK Paul, MA Samad, MA Mamun and MAZ Chowdhury, 2011. Proceedings of the Pakistan Academy of Sciences, 48: 89-93.

2. Almela V, S Zaragota, E Promo-Milo and M Augusti, 1994. Hormonal control of splitting in Nova mandarin fruit. Journal of Horticultural Science, 69: 969-973.

3. Anonymous, 2009. Fruit traders are fined for practicing chemical fruit ripening (in Bengali), The Daily Protham Alo, 17 October 2009.

4. Anonymous, 2010a. Destruction of chemically-treated 60 mounds mangoes in Jatrabari, Dhaka (in Bengail), The Daily Protham Alo, 6 May, 2010.

5. Anonymous, 2010b. Destruction of 9 tons chemically-ripen mangoes in the capital (in Bengail), The Daily Samakal, 18 May, 2010.

6. Anonymous, 2014a. Kushtia, Manikganj watermelon cleared. The Daily Independent. 6 May 2014.

7. Anonymous, 2014b. Two sibling die, 19 fall sick after eating watermelon. The Daily Sun, 21 April 2014. Anonymous. 2014c. Cabinet okays Formalin Control Act 2014. The Daily Sun, 01 July 2014.

8. BBS, 2010. Preliminary Report: Bangladesh Household Income Expenditure Survey (HIES). Bangladesh Bureau of Statistics (BBS), Statistics Division, Ministry of Planning, Government of the People's Republic of Bangladesh.

9. Bhuiyan MH, MS Ali and MM Molla, 2009. Effects of Using Chemicals and Hormones for Cultivation and Marketing of Vegetables and Banana. Final Report (CF 14/07), NFPCSP-FAO, Bangladesh.

10. FAO/WHO, 2003. Diet, nutrition and the prevention of chronic diseases. Report of a joint FAO/WHO. Expert consumption WHO Technical Report Series 916. Geneva. World Health Organization.

11. FAO/WHO, 2002. Global forum of food safety regulators. Marrakech, Morocco. [http://www.fao.org/DOCREP/MEETING/004/AB428E.HTM Agenda Item 4.2a,GF/CRD Iran-1]. 28-30 January.

12. Food Safety Act, 2013. Food Safety Act (Law No. 43, 2013). Bangladesh Gazette, Thursday, October 2013, pp. 8823-8869.

13. Green MA, MA Heumann, HM Wehr, LR Foster, LP Williams, JrJA Polder, CL Morgan, SL Wagner, LA Wanke and JM Witt, 1987. An outbreak of watermelon-borne pesticide toxicity. American Journal of Public Health. 77: 1431-1434.

14. Hassan MK, 2010. A Guide to Postharvest Handling of Fruits and Vegetables. Department of Horticulture, Bangladesh Agricultural University, Mymensingh, with financial support from the USAID and EU and technical support from FAO. p. 117.

15. Hassan MK, BLD Chowdhury and N Akhther, 2010. Final Report- Postharvest Loss Assessment: A Study to Formulate Policy for Loss Reduction of Fruits and Vegetables and Socio-Economic Uplift of the Stakeholders, Department of Horticulture, Bangladesh Agricultural University, Mymensingh (Funded by USAID and EU \& Jointly implemented by FAO and FPMU of MoFDM). p. 189.

16. Hassan MK, SK Raha and N Akhther, 2012. Final Report- Improving the Performance of Marketing Systems of Fruits and Vegetables in Bangladesh, Department of Horticulture, Bangladesh Agricultural University, Mymensingh (funded by EU \& USAID and implemented by FAO and Ministry of Food). p. 179.

17. Hofman PJ, 1998. Production factors influence fruit quality and response to postharvest treatments. In 'Proceedings of an International Workshop held at Chiang Mai, Thailand, 22-23 May, 1995 on Disease Control and Storage Life Extension of Fruit' (Eds LM Coates, PJ Hofman and GI Johnson) pp. 6-18 (Australian Centre for International Agricultural Research, ACIAR Proceedings No. 81, Canberra).

18. Itai A, K Tanabe, F Tamura and S Suzaki, 1995. Synthetic cytokinins control persimmon fruit shape, size and quality. Journal of Horticultural Science, 70: 867-873.

19. Islam MR, M Jahiruddin, MR Islam, MA Alim and M Akhtaruzzaman, 2013. Final ReportConsumption of Unsafe Foods: Evidence from Heavy Metal, Mineral and Trace Element Contamination. Department of Soil Science, Bangladesh Agricultural University, Mymensingh (Funded by USAID and EU \& Jointly implemented by FAO and FPMU of Ministry of Food). p. 125.

20. Islam MS, 2008. Fruit ripening technology is essential for commercial agriculture (in Bengali), The Daily Protham Alo, 19 August 2008. 
21. Islam MW, KMG Dastogeer, I Hamim, MDH Prodhan and M Ashrafuzzaman, 2014. Detection and quantification of pesticide residues in selected vegetables in Bangladesh. Journal of Phytopathology and Pest Management, 1: 17-30.

22. Islam S, MR Islam, M Jahiruddin and MR Imtiaz, 2009. Effect of arsenic contamination on arsenic and nutrient concentrations of Boro rice genotypes. Journal of Environmental Science and Natural Resources, 2: 103-110.

23. Jahiruddin MK, Egashira, M Tani, AZM Moslehuddin, K Kurosawa and MZ Rahman, 2009. Arsenic concentration in vegetables collected from Maruna village, Jessore and its implication for health risk. Proceedings of Seminar on Pathway of Arsenic from Groundwater Contamination to Human Health Hazard. pp. 1-12. 03 March 2009.

24. Lokeshwari H and GT Chandrappa, 2006, Impact of heavy metal contamination of Bellandur Lake on soil and cultivated vegetation. Current Science, 91: 1-6.

25. Lone M.I., S. Saleem, T. Mahmood, K. Saifullah and G. Hussain, 2003. International Journal of Agriculture and Biology, 5(4): 533-535.

26. Morol S, 2014. Maximum death in the country is due to stroke. The Daily Protham Alo (In Bengali), 19 December 2014.

27. Naser, HM, S Sultana, NU Mahmud, R Gomes and S Noor, 2011. Heavy metal levels in vegetables with growth stage and plant species variations. Bangladesh Journal of Agricultural Research, 36(4): 563-574.

28. NFP (National Food Policy), 2008. Safe, Quality Food Supply, Area of Intervention 3.6, The National Food Policy Plan of Action 2008-2015, p. 37.

29. NFP (National Food Policy), 2006. Safe, Quality Food Supply, Strategy 3.5 (Cited in NAF, 2008, National Food Policy Plan of Action 2008-2015, p. 131).

30. Pradhan SK, A Bandyopadhyay, SK Mitra and SK Sen, 1988. Effects of growth substances on fruit size, yield and quality of banana var. Giant Governor. Progressive Horticulture, 20, 326-330.

31. Rasul $\mathrm{CH}, 2013$. Alarming situation of food adulteration (Editorial). Bangladesh Medical Journal Khulna, 46: 1-2.

32. Shajal NK, 2008. Artificially-Ripen Pineapples are Tasteless (in Bengali). The Daily Protham Alo, 13 September, 2008.

33. Suslow TV, 2003. Key points of control and management of microbial food safety: information for growers, packers, and handlers of fresh-consumed horticultural products. Publication 8102, Division of Agriculture and Natural Resources, University of California. p.7.

34. Uddin MB, 2013. Co-ordinated Project on Contaminants and Adulterants in Food Chain and their Mitigation: BAU Component. Department of Food Technology and Rural Industries, Bangladesh Agricultural University, Mymensingh.

35. Whahid F, MK Hassan, BLD Chowdhury and N Akhther, 2012. A Study on chemical and conventional methods of banana ripening. Journal of Fruit Science and Technology, 2: 133-141.

36. Wills RBH, WB McGlasson, D Graham and DC Joyce, 2004. Postharvest: Introduction to the Physiology and handling Fruits, Vegetables and Ornamentals (4th Edition). University of New South Wales Press Ltd., Sydney 2052, Australia, 262p. 